\title{
EDITORIAL: NEW MODELS
}

\author{
Christopher Fox (D)
}

This is not a consciously themed issue, but it is an issue in which a particular way of thinking seems to have serendipitously emerged. Kagel, Wandelweiser, Zorn, a recent song cycle, politically engaged music, rhizomatic analysis: these are all standard fare on the new music menu, but here they are approached from rather less familiar perspectives. For example, the constellation of composers who are seen as forming the Wandelweiser collective are usually thought of as the makers of music that is both quiet and quietist. Its quietness regularly verges on silence, to the extent that it can sometimes seem that the sounds of the music are there as much as to demarcate passages of silence as to be heard for what they might signify. Often this is interpreted as a form of musical quietism: making music so quietly can hardly be an effective way of asserting one's compositional identity. Ed Cooper's article suggests otherwise.

Or consider John Zorn, although a search through TEMPO back numbers shows that this is not something that the features section of the journal has ever done before. His music is well known and much recorded, his scores widely circulated and often performed. But what are we hearing when we listen to a Zorn piece, particularly those that involve recordings of the musicians with whom he regularly collaborates? Zorn is usually generous in his suggestions of subject matter, through titles, dedications and other texts, but how does the music represent this subject matter? Maurice Windleburn's article on Zorn's Interzone considers its literary source and offers a plausible, and surprisingly literal, reading.

One more example, because I need to explain why TEMPO's usual focus on recent music has been extended to include Mauricio Kagel's 1970 music-theatre work Staatstheater. In part this is because I believe Staatstheater is a work that should be far better known in performance, rather than just as a beautiful score much pored over by generations of composers. Since its first production in Hamburg in 1971 it has received very few further complete performances and, as far as I aware, no operatic main-stage productions outside Germany. This has, in turn, led to hundreds of pale imitations of its witty deconstruction of the apparatus of every sort of theatrical (and not so theatrical) performance. Bethany Younge proposes a radical new reading of Kagel's music-theatrical imagination: not another set of songs for mad kings, but a depiction of disability as no more than another form of difference.

All these articles demonstrate that sometimes we need to remodel the ways in which we think about music. The preparation of Bethany Younge's article for publication has also demonstrated that we need new models for the dissemination of music. The article contains just six music examples yet the publishers of the score initially wanted to charge a fee for the use of each of these examples. I want musicians to be rewarded properly for their work but it is TEMPO policy that we will not pay for music examples, not because Kagel died in 2008, not 
because the published score is an unedited facsimile of his manuscript, nor because the rights from a performance of the work would yield far more income, but because music researchers who work on new and recent composed music are few and far between and need to be cherished, not exploited.

It is with regret that we mark the death of the composer Justin Connolly (1933-2020). I was fortunate enough to meet Justin on a number of occasions at the University of Huddersfield during his time as an external examiner there. He was, perhaps typically of his generation of composers, rather more robust in his assessment of students' work than is now the norm, but he was also unfailingly perceptive, able to understand what a young composer's aspirations might be, even when he thought that they were misguided and poorly realised.

His own music was always distinguished by the clarity of its forming - sharply defined motives, deftly and dramatically presented and transformed - and the brass quintet Cinquepaces is a fine early example of his craft. Written in 1965 for the Philip Jones Brass Ensemble, Connolly's opus 5 is a sequence of three 'Cinquepace' movements, their dancing rhythms almost neo-classical in flavour, preceded by a fragmentary prelude and interspersed by two more lyrically sustained interludes. A recording of the piece was released in 1973 as an Argo LP at a time when a portrait album on that label was a mark of a composer's success; the recording is still available as a CD.

Connolly's career as a composer began rather late. He had initially trained as a lawyer and by the time his work started to receive the attention of performers and promoters it was somewhat eclipsed by other composers of his generation - Birtwistle, Davies, Goehr whose work was similarly modernist but rather more ostentatious. In a 2012 TEMPO article Anthony Gilbert summarised Connolly's music: 'It is very challenging, but by no means unperformable, nor indeed incomprehensible ... In fact none of the techniques in his vocabulary are terribly obscure ... They have consistency and logic, as well as interesting interrelations'; ${ }^{1}$ perhaps only in England could such caveats be intended as praise. Connolly's music deserves to be heard: it is music that celebrates its time and its making.

\footnotetext{
1 Anthony Gilbert, 'Kaleidoscopes and a Labyrinth - The Musical Vision of Justin Connolly', TEMPO, 66, no. 260 (2012), p. 22.
} 